\title{
Identification of suitable substitute for Sarpagandha (Rauvolfia serpentina (L.) Benth. ex Kurz) by phytochemical and pharmacological evaluation
}

\author{
Sulaiman C. T. ${ }^{*}$ (D) Jyothi C.K., Jinu Krishnan Unnithan, Prabhukumar K.M. and Indira Balachandran
}

\begin{abstract}
Background: Sarpagandha is an important Ayurveda drug used for treating many diseases including high blood pressure. Rauvolfia serpentina is the genuine source plant for Sarpagandha and it is a critically endangered species belonging to the family Apocynaceae. The present study is aimed at finding out an appropriate substitute for the endangered species $R$. serpentina by evaluating the phytochemistry and biological activities of allied species such as Rauvolfia tetraphylla L, Rauvolfia hookeri S.R.Sriniv. \& Chithra, Rauvolfia micrantha Hook.f., and Rauvolfia verticillata (Lour.) Baill.

Results: The result indicated that the root of $R$. serpentina is phytochemically similar with that of $R$. tetraphylla. Chemical profiling using HPTLC showed similar chemical profiles for $R$. serpentina and $R$. tetraphylla. LC/MS characterization of various species showed that most of the active alkaloids are common for both $R$. serpentina and R. tetraphylla. Anti-hypertensive activity and analgesic activity were evaluated in experimental animal model. Rauvolfia serpentina and $R$. tetraphylla showed comparatively significant reduction in systolic and diastolic pressure. Comparable analgesic activity was also shown by $R$. serpentina and $R$. tetraphylla.

Conclusion: On the basis of phytochemical and pharmacological evaluation, it was concluded that the root of $R$. tetraphylla can be used as a validated substitute for Sarpagandha.
\end{abstract}

Keywords: Rauvolfia, HPTLC, LC/MS, Anti-hypertensive activity, Analgesic activity

\section{Background}

In Ayurveda, Sarpagandha is used for the treatment of high blood pressure, insomnia, asthma, acute stomach ache and painful delivery and for mental illness such as neuropsychiatric disorders, psychosis, and schizophrenia. The root of Rauvolfia serpentina is the genuine source drug of Sarpagandha. It is also used in the treatment of snake-bite, insect stings, mental disorders, gastric tumor, general weakness, goiter, hysteria, insomnia, insanity, lipoma, paraplegia, paratyphoid, piles, pneumonia,

\footnotetext{
*Correspondence: sulaimanct@aryavaidyasala.com; sImnct@gmail.com Phytochemistry Division, Centre for Medicinal Plants Research, Arya Vaidya Sala, Kottakkal-676503, Malappuram, Kerala, India
}

splenomegaly, stomach disorder, tonsillitis, traumatic wound, tuberculosis, and vertigo [1].

Genus Rauvolfia, belonging to the family Apocynaceae, comprises more than 80 species, which are distributed in tropical climatic conditions. Rauvolfia serpentina is well known for the presence of indole alkaloids. Reserpine is the most prominent of these alkaloids and is useful in the treatment of hypertension, cardiovascular diseases, nervous disorders, and as a tranquilizing agent that is in great demand by modern pharmaceutical industries [2].

Rauvolfia tetraphylla popularly known as "devil pepper" is a woody shrub commonly available in India. It is native to West Indies but naturalized in South India [3].

\section{Springer Open}

(0) The Author(s). 2020 Open Access This article is licensed under a Creative Commons Attribution 4.0 International License, which permits use, sharing, adaptation, distribution and reproduction in any medium or format, as long as you give appropriate credit to the original author(s) and the source, provide a link to the Creative Commons licence, and indicate if changes were made. The images or other third party material in this article are included in the article's Creative Commons licence, unless indicated otherwise in a credit line to the material. If material is not included in the article's Creative Commons licence and your intended use is not permitted by statutory regulation or exceeds the permitted use, you will need to obtain permission directly from the copyright holder. To view a copy of this licence, visit http://creativecommons.org/licenses/by/4.0/. 
It is an ethnomedicinally important plant and is used against snakebite, to stimulate uterine contraction and to facilitate difficult childbirth cases. Rauvolfia hookeri is a large dichotomously branched shrub belonging to the family Apocynaceae. It is an endemic south Indian species containing many indole alkaloids [2]. Rauvolfia micrantha is an annual shrub, reaching up to 1.5 to $2 \mathrm{~m}$ high. Stems are sparingly branched. Leaves are simple, alternate, elliptic lanceolate, $5-10 \mathrm{~cm} \times 3-4 \mathrm{~cm}$, acuminate, peduncle terminal, erect, 4-6 flowered. Rauvolfia verticillata is an erect shrub growing up to $3 \mathrm{~m}$ tall and also a prolific source of heterocyclic indole alkaloids [4].

Nowadays, the herbal drug industry is getting often disrupted due to non-availability of good quality raw materials for manufacturing drugs. The acute shortage of plant raw materials is adversely affecting the quality of finished herbal products, as manufacturers are forced to buy sub standard raw material at double the prices pushing many manufacturers at the brink of shutting down of their industry. The habitat loss by export of medicinal plants collected from wild sources finally leads to severe and irreplaceable loss of genetic stock of many of these species. In India, the Ministry of Environment and Forests has banned export of 29 species including some popularly used drugs in Ayurvedic formulations like Sarpagandha [5].

Rauvolfia serpentina is identified as a critically endangered species [6]. Due to high demand and unavailability, the roots of Rauvolfia serpentina are usually adulterated with other species like Ophiorrhiza mungos, white-flowered and red-flowered Clerodendrum species and Tabernaemontana divaricata. Substitutes were used and recommended in the ancient texts for plants that were scarce to obtain. In this way, different regions in the country have come to use different botanical sources for some of the classical plants [7]. In industry, Sarpagandha is commonly substituted with the root of other Rauvolfia species.

Identification of a scientifically validated substitute from allied/related species for the endangered medicinal plant has a great importance in the herbal drug industry as it exterminates the unauthorized substitution and adulteration. The unscientific substitution may affect the quality of herbal preparations adversely. No previous scientific studies are available regarding the identification of substitute for this selected species. The objective of the present study is to find out an appropriate substitute for the root of $R$. serpentina by evaluating the phytochemical and pharmacological properties of its allied species.

\section{Methods}

\subsection{Chemicals and reagents}

Folin-Ciocalteu reagent was procured from Sisco Research Laboratory (SRL), Mumbai, India. LC/MS grade solvents and analytical standards such as DOCA, enalapril maleate (powder), gallic acid, quercetin, reserpine, ajmalicine, and atropine were procured from Sigma Chemicals Co. (Bangalore, India). Aspirin tablets (Cipla, India) were procured from the local pharmacy. All other chemicals employed were of standard analytical grade from Merck India.

\subsection{Collection of plant materials}

Various species such as Rauvolfia serpentina, $R$. hookeri, $R$. micrantha, $R$. tetraphylla, and $R$. verticillata were collected from different zones of south India (Table 1). The materials were authenticated and voucher specimens were added to the herbarium.

\subsection{Extraction of materials}

The plant materials were shade dried and pulverized. Five grams each of the sample was successively extracted with various solvents like n-hexane, chloroform, and methanol by refluxing for $6 \mathrm{~h}$. Crude extracts were prepared separately with methanol, water, and hydro alcohol (ethanol: water 50:50) using the reflux extraction method. The process was repeated in triplicates. The final extracts were pooled and concentrated at $40{ }^{\circ} \mathrm{C}$ using a rotary evaporator (Heidolph, Germany) and it was made up to $100 \mathrm{ml}$ with respective solvents in standard flasks. The extracts were kept under refrigerator until the various phytochemical analyses were over.

Two hundred fifty grams of various samples were separately extracted for pharmacological studies with water using the soxhlet extraction method for $72 \mathrm{~h}$. The final extracts were concentrated to dryness under reduced pressure using a rotary evaporator (Heidolph, Germany). The sample details are presented in Table 2.

\subsection{Estimation of total alkaloids}

Total alkaloid was estimated spectrophotometrically based on the reaction of alkaloids with bromocresol green [8]. The method consisted of extraction of alkaloid by acid treatment of the extracts followed by basification and extraction with chloroform. Different concentrations of atropine were used to plot the calibration curve. The absorbance of the complex in chloroform was measured at $470 \mathrm{~nm}$ against blank using a spectrophotometer.

\subsection{Estimation of total poly phenolics}

Polyphenols such as phenolics and flavonoids were estimated spectrophotometrically. The total phenolic content (TPC) was determined using Folin-Ciocalteu reagent $[9,10]$. TPC was expressed as gallic acid equivalents (GAE) in $\mathrm{mg} / \mathrm{g}$ of sample. Total flavonoid content (TFC) was measured by aluminum chloride colorimetric assay [11] and expressed as milligram quercetin equivalents (mg EQ). 
Table 1 Details of plant collections

\begin{tabular}{llll}
\hline SI. no. & Species name & Locality & Voucher specimen no. \\
\hline 1 & Rauvolfia serpentina (L.) Benth. ex Kurz & Kasargode, Kerala & CMPR 9997 \\
CMPR 8922 \\
CMPR 8909 \\
\\
& & Kozhikode, Kerala \\
& Thrissur, Kerala & CMPR 9671 \\
2 & Rauvolfia hookeri Sriniv. \& Chithra & Breymore, Agasthyamalai Biosphere Reserve, Trivandrum, Kerala \\
3 & Rauvolfia micrantha Hook. f. & Wagamon, Idukki, Kerala & CMPR 9548 \\
4 & Rauvolfia tetraphylla L. & Thenhipalam, Malappuram, Kerala & CMPR 9395 \\
5 & Rauvolfia verticillata (Lour.) Baill. & Wagamon, Idukki, Kerala & CMPR 9549 \\
& & & CMPR 9593 \\
\hline
\end{tabular}

2.6 High-performance thin layer chromatographic (HPTLC) analysis

HPTLC analysis was performed using CAMAG HPTLC system (Switzerland). Samples were applied using CAMAG ATS 4 on aluminum-backed pre-coated silica gel $60 \mathrm{~F}_{254}$ HPTLC plate (Merck India). Mobile phase was standardized as toluene, ethyl acetate, and methanol in the ratio of $7: 3: 1$. The chromatogram was developed in a saturated Twin Trough chromatographic chamber (Camag, Switzerland). The developed plate was visualized under UV at $254 \mathrm{~nm}$ and $366 \mathrm{~nm}$ and in visible light after derivetizing with anisaldehyde-sulfuric acid reagent followed by heating at $105^{\circ} \mathrm{C}$ for $5 \mathrm{~min}$.

\subsection{Characterization of alkaloids}

Five grams each of dried root of five species was extracted with ethyl alcohol $(100 \mathrm{ml})$ by cold percolation up to $72 \mathrm{~h}$ with frequent stirring. It was then concentrated to dryness under reduced pressure in a rotary evaporator (Heidolph, Germany) and treated with dilute $\mathrm{HCl}$. The acid layer was washed with $\mathrm{CHCl}_{3}$ three times $(10 \times 3)$. Basified the extract with ammonia and extracted with $\mathrm{CHCl}_{3}(10 \mathrm{ml})$. The final alkaloid fraction was re-dissolved in HPLC grade chloroform. The preliminary analysis was carried out by HPTLC profiling. Characterization was done by LC/MS-MS analysis.

\subsection{LC/MS characterization of alkaloid fractions}

LC-ESI/MS analysis was conducted on Agilent 6520 accurate mass Q-TOF-LC/MS coupled with Agilent LC 1200 equipped with Extend-C18 column of $1.8 \mu \mathrm{m}, 2.1 \times$ $50 \mathrm{~mm}$. Isocratic elution was performed with ACN with $0.1 \%$ ammonium formate at a constant flow rate of 0.8

Table 2 Sample design

\begin{tabular}{lll}
\hline SI. no & Sample code & Sample details \\
\hline 1 & RSR & R. serpentina root \\
2 & RHR & R. hookeri root \\
3 & RMR & R. micrantha root \\
4 & RTR & R. tetraphylla root \\
5 & RVR & R. verticillata root \\
\hline
\end{tabular}

$\mathrm{ml} / \mathrm{min}$. The MS analysis was performed using ESI in the positive mode. The conditions for mass spectrometry were drying gas (nitrogen) flow $5 \mathrm{~L} / \mathrm{min}$; nebulizer pressure 40 psig; drying gas temperature $325^{\circ} \mathrm{C}$; capillary voltage $+3000 \mathrm{~V}$; fragmentor volt 125 $\mathrm{V}$; Oct RF Vpp $750 \mathrm{~V}$. The mass fragmentation was performed with varying collision energy $4 \mathrm{~V} / 100 \mathrm{DA}$ with an offset of $8 \mathrm{~V}$.

\subsection{Evaluation of anti-hypertensive activity}

DOCA-salt-induced hypertension model was used for the evaluation of anti-hypertensive activity [12]. Wistar albino rats $(n=6)$ of weighing 220-250 g were obtained from animal house of Karpagam University, Tamil Nadu, India, and used for the study. The animals were placed at random and allocated to treatment groups in polypropylene cages with paddy husk as bedding. Animals were housed at a temperature of $24 \pm 20^{\circ} \mathrm{C}$ and relative humidity of $30-70 \%$. A light and dark cycle was followed. All animals were fed on a standard balance diet and provided with water ad libitum. The study protocol was approved by the Institutional Animal Ethics Committee (Approval No: KAHE/IAEC/2018/21-04/002). All institutional and national guidelines for the care and use of laboratory animals were followed.

All animals were maintained for 2 weeks and BP was measured. The systolic and diastolic blood pressure was determined by the tail-cuff method (BP-2000-MR-2, blood pressure analysis system for mice and rats). The animals were placed in the chamber at an ambient temperature of $30-34{ }^{\circ} \mathrm{C}$ for $15 \mathrm{~min}$, and from each animal, blood pressure values were recorded. At the end of the experiment, animals were not sacrificed and were shifted to separate cages.

Animals were given, weekly twice, subcutaneous injections of DOCA $(20 \mathrm{mg} / \mathrm{kg} \mathrm{BW} \mathrm{sc})$ in olive oil and salt were administered by substitution of $1 \% \mathrm{NaCl}$ solution for drinking water ad libitum throughout the experimental period for 4 weeks then BP was measured. Deoxycorticosterone acetate (DOCA) is one of the most common high-salt diet used for anti-hypertensive experimental model. 
The rats were randomly divided into nine groups of six rats each. Group one served as normal control and group II treated with DOCA-salt and served as hypertension control. Group III treated with enalapril $(48 \mathrm{mg} /$ $\mathrm{kg}$, oral), group IV to group IX were hypertensive rats which received different extracts at a dose of $150 \mathrm{mg} / \mathrm{kg}$ BW for 5 weeks (Table 3). The extracts were prepared from a plant material having a high safety margin and the dose was fixed based on the previous methods [13].

\subsection{Evaluation of analgesic activity}

\subsubsection{Formalin test}

The Wistar albino rats weighing between 150 to $180 \mathrm{~g}$ were obtained from animal house of Karpagam University, Tamil Nadu, India, and were used for the study. The study protocol was approved by the Institutional Animal Ethics Committee (Approval No: KAHE/IAEC/ 2018/21-04/001). All institutional and national guidelines for the care and use of laboratory animals were followed. Fifty microliter of a 5\% formalin solution was injected subcutaneously into the dorsal surface of the right or left hind paw of the rat using a 29-gage needle (U-100 Insulin Syringe, Beckton and Dickinson, Dublin, Ireland). The $5 \%$ formalin solution was prepared by dilution with normal saline of the commercial $10 \%$ formalin solution. The total number of flinches of the hind paw and/or the hind quarters was recorded by visual observation for $10 \mathrm{~min}$ periods for total observation duration of $2 \mathrm{~h}$ following injection of formalin. In addition, licking/ biting of the injected paw was recorded using a digital time-out stopwatch as total licking time (s) per $10 \mathrm{~min}$ observation period for a total duration of $2 \mathrm{~h}$ following injection of formalin. Control rats, injected subcutaneously in the dorsal surface of the right hind paw with $50 \mu \mathrm{l}$ normal saline, did not show these typical nociceptive behaviors [14].

\subsubsection{Hot plate method}

The Wistar albino rats weighing between 150 to $180 \mathrm{~g}$ were used for the study. The analgesic activity was examined using the hot plate method. Animals were

Table 3 Experimental design

\begin{tabular}{ll}
\hline Group & Treatment \\
\hline Group I control & Normal \\
Group II BP group & DOCA treated (20 mg/kg BW) \\
Group III (standard) & DOCA treated + Enalapril inj. (48 mg $/ \mathrm{kg}$, oral) \\
Group IV (RSR) & DOCA treated $+150 \mathrm{mg} / \mathrm{kg}$ of RSR \\
Group V (RHR) & DOCA treated $+150 \mathrm{mg} / \mathrm{kg}$ of RHR \\
Group VI (RMR) & DOCA treated $+150 \mathrm{mg} / \mathrm{kg}$ of RMR \\
Group VII (RTR) & DOCA treated $+150 \mathrm{mg} / \mathrm{kg}$ of RTR \\
Group VIII (RVR) & DOCA treated $+150 \mathrm{mg} / \mathrm{kg}$ of RVR \\
\hline
\end{tabular}

divided into VIII groups, each group containing six animals each. Group I served as the positive control with no protection. Group II animals received the standard drug of aspirin $150 \mathrm{mg} / \mathrm{kg}$ body weight, whereas group III to VIII animals were orally administered the various plant extracts at the dose of $150 \mathrm{mg} / \mathrm{kg}$ body weight respectively. The temperature of the hot plate was maintained $55 \pm 1{ }^{\circ} \mathrm{C}$, rats were placed on the hot plate, and time in seconds for paw licking or jumping was recorded as basal reaction time. Cutoff time in the absence of a response was $15 \mathrm{~s}$ to prevent the animals from being burnt. The reaction time in seconds (latency period) was observed on a hot plate, the time taken for the rat to react to the thermal pain by licking its paw or attempting to jump out. Observations were made after $60 \mathrm{~min}$, the animals are placed on the hot plate and the observations were recorded, and at the time interval of 90 and $120 \mathrm{~min}$. After the experiment, animals were not sacrificed and were shifted to separate cages.

\subsection{Data analysis}

For determination of significant intergroup differences of each parameter one-way analysis of variance (ANOVA) was carried out. Dunnet's test was used for individual comparisons after significant ANOVA results. The differences with $p<0.05$ was considered statistically significant. The Graphpad Prism-6 software (Graphpad software, Inc., USA) was used for the statistical analysis.

\section{Results}

\subsection{Phytochemical characterization}

Various extracts of selected species were subjected to different phytochemical analyses including estimation of important class of compounds like alkaloids, phenolics, and flavonoids. Chemical profiling of different extracts such as n-hexane, chloroform, methanol, hydro alcohol, and water were done using HPTLC analysis. Metabolite profiling of selected species was carried out by LC-MS/ MS analysis.

Rauvolfia is well known for its alkaloid content [4] and the same was estimated based on the reaction with bromocresol green (BCG). The highest alkaloid content was showed by $R$. tetraphylla $(0.90 \%)$, followed by $R$. serpentina $(0.48 \%)$. Rauvolfia verticillata showed the least alkaloid content $(0.22 \%)$. The alkaloid content of $R$. serpentina is in agreement with the previous report [15]. When compared to allied species, the quantity of alkaloids in $R$. tetraphylla is much higher than that of the genuine drug (Table 4).

Total polyphenolic content of various Rauvolfia species was estimated spectrophotometrically. Total phenolic content (TPC) and total flavonoid content (TFC) were calculated from the calibration curve of gallic acid $\left(R^{2}=0.994\right)$ and quercetin $\left(R^{2}=0.995\right)$ respectively (Table 4$)$. 
Table 4 Estimation of major phytochemicals in various Rauvolfia species

\begin{tabular}{lllll}
\hline SI. no & Sample & Total alkaloids & Total phenolics & Total flavonoids \\
\hline 1 & R. serpentina & $\mathbf{0 . 4 8}$ & $\mathbf{5 . 2 0}$ & $\mathbf{1 . 8 0}$ \\
2 & R. hookeri & 0.33 & 5.67 & 5.50 \\
3 & R. micrantha & 0.36 & 7.57 & 6.70 \\
4 & R. tetraphylla & $\mathbf{0 . 9 0}$ & $\mathbf{8 . 1 0}$ & $\mathbf{6 . 1 0}$ \\
5 & R. verticillata & 0.22 & 12.33 & 10.30 \\
\hline
\end{tabular}

The highest phenolic content was observed for $R$. verticillata (12.33 mg Eq Ga) followed by $R$. tetraphylla ( $8.10 \mathrm{mg}$ Eq Ga). The phenolic content of $R$. serpentina is found to be $5.20 \mathrm{mg}$ equivalence of gallic acid. In the case of total flavonoids, $R$. verticillata showed the highest value (10.30 mg Eq QE) followed by $R$. tetraphylla. The chemical contents of $R$. tetraphylla are much higher than that of $R$. serpentina. The estimation of total polyphenolics of Rauvolfia species revealed significant diversity among the species. Variation of phenolic contents among the species was previously reported for many other species also [16, 17].

Chromatographic fingerprint analysis is found to be a cogent and realistic approach for the quality assessment and species authentication of raw drugs. It utilizes chromatographic techniques to construct specific patterns of recognition for medicinal plants. Comparative HPTLC profiles were developed for the root of various species (Fig. 1). At $254 \mathrm{~nm}, \mathrm{n}$-hexane extract showed a few bands which indicate that low polar compounds with chemical quenching is very less in Rauvolfia species. A common band with $R_{\mathrm{f}} 0.60$ was observed in $R$ serpentina, $R$. micrantha, and $R$. verticillata. Compound at $R_{\mathrm{f}}$ 0.29 is common for $R$. hookeri and $R$. micrantha. At 366 $\mathrm{nm}$, major bands were observed at $0.17,0.55$, and 0.75 for $R$. serpentina. Two fluorescent bands at 0.06 (blue) and 0.62 (yellow) were observed for $R$. hookeri, $R$. micrantha, and $R$. verticillata. A fluorescent band at 0.29 was found to be absent in $R$. serpentina only. Two bands at 0.77 and 0.82 were shown by $R$. micrantha, $R$. tetraphylla, and $R$. verticillata.

HPTLC profile of chloroform extracts is almost similar in their banding pattern and it is the indication of presence of similar phytoconstituents in all the selected species. Major bands were observed at $R_{\mathrm{f}} 0.06,0.35,0.41$ as common bands in all the selected species. Band at $R_{\mathrm{f}}$ 0.29 is common for four species other than $R$. serpentina. A compound at $R_{\mathrm{f}} 0.15$ was found to be absent in $R$. verticillata. A band at 0.61 is absent only for $R$. tetraphylla. On evaluating under $366 \mathrm{~nm}$, a common band at 0.39 with blue fluorescence was observed for all the selected species. Compound with $R_{\mathrm{f}} 0.34$ is absent only in $R$. verticillata. Two bands with blue fluorescence at 0.10 and 0.17 were specifically found in $R$. tetraphylla. A blue fluorescence at 0.23 was found as the common band for $R$. serpentina, $R$. tetraphylla, and $R$. verticillata. Two specific bands at 0.29 (yellow fluorescent) and 0.59 (blue florescence) were observed for $R$. hookeri, $R$. micrantha, and $R$. verticillata. At 0.52 , a band with yellow fluorescence was shown by $R$. serpentina and $R$. tetraphylla. An intense fluorescent band at 0.75 was observed in $R$. serpentina which was not observed in any other species.

Chemical profiling of crude extracts was also carried out with methanol, water, and hydro alcohol (Figs. 2, 3, and 4). HPTLC profiles of crude extracts also showed common compounds with matching $R_{\mathrm{f}}$ values. Hydro alcoholic extracts showed bands with comparatively high resolution among the three crude extracts; this may be due to the optimum polarity of extraction medium with an aqueous and alcoholic combination. All the crude
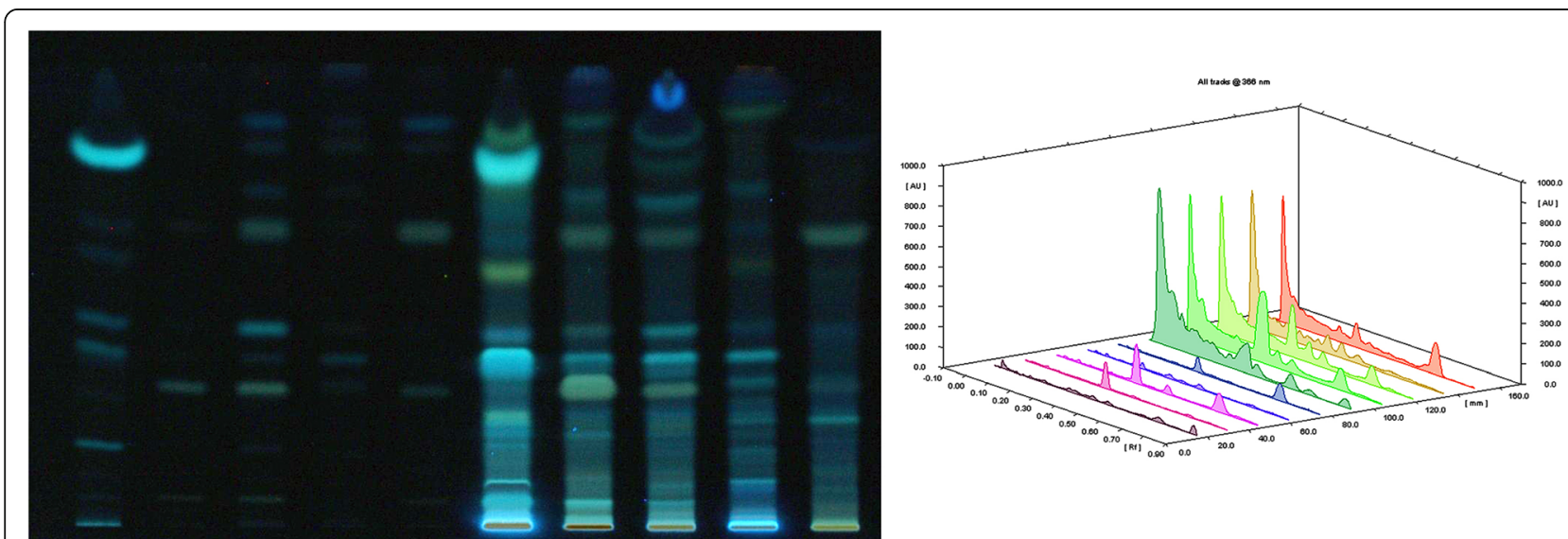

RSR RHR RMR RTR RVR RSR RHR RMR RTR RVR

Fig. 1 HPTLC profile of sequential n-hexane and chloroform extracts of various Rauvolfia species. Tracks: 1-5, n-hexane extracts; 6-10 chloroform extracts: RSR: R. serpentina root, RHR: $R$. hookeri root, RMR: $R$. micrantha root, RTR: $R$. tetraphylla root, RVR: $R$. verticillata root 


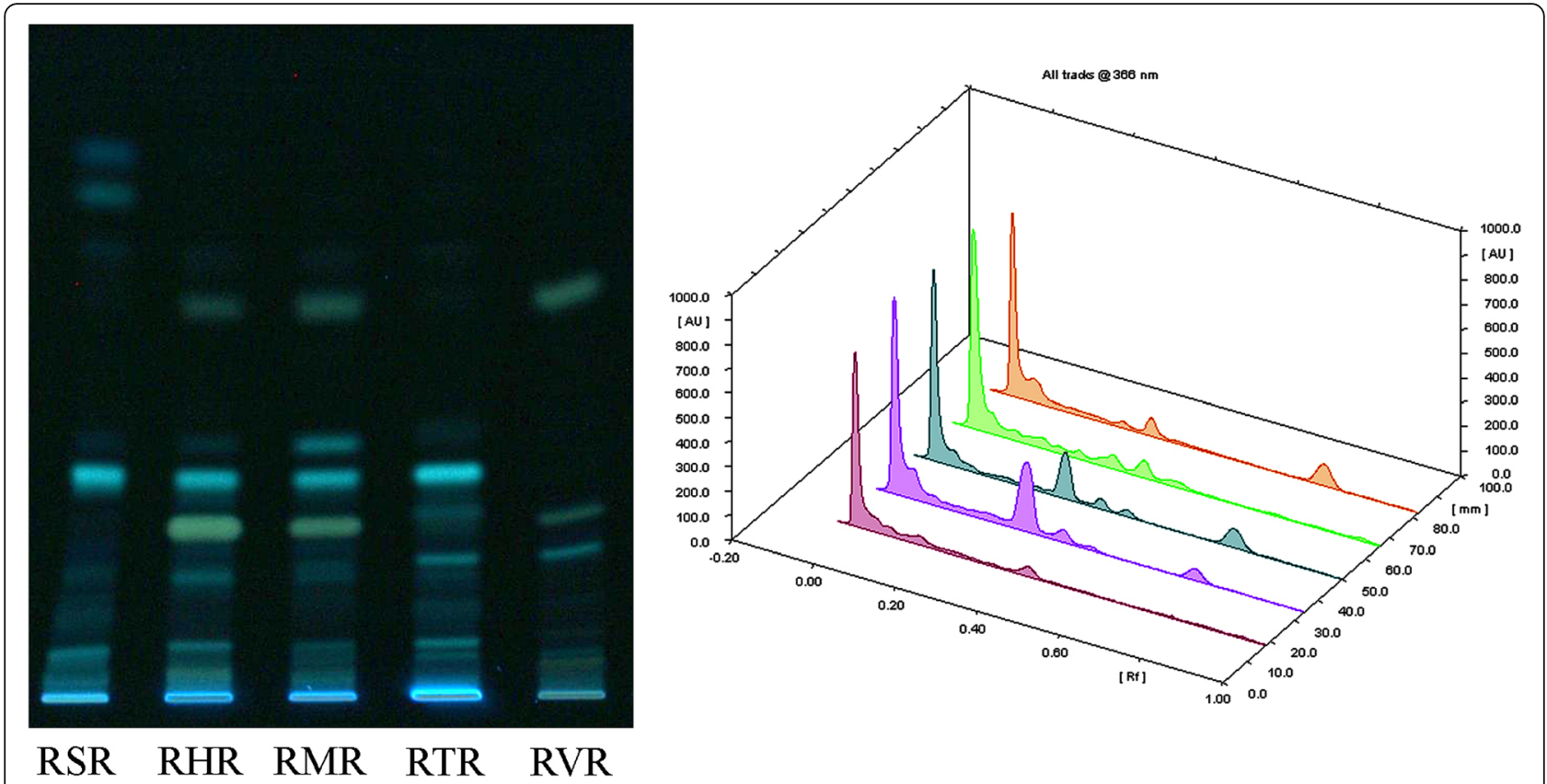

Fig. 2 HPTLC profile of methanol extracts of various Rauvolfia species. RSR: $R$. serpentina root, RHR: $R$. hookeri root, RMR: $R$. micrantha root, RTR: $R$. tetraphylla root, RVR: $R$. verticillata root

extracts also showed common bands at $254 \mathrm{~nm}$ and 366 $\mathrm{nm}$. Scanned spectrum of different tracks confirmed the similarities of separated bands.

The developed fingerprint pattern of genuine and allied species can be used to determine not only the absence or presence of markers of interest but the ratio of all detectable phytoconstituents as well. HPTLC profiling with spectral scanning at UV and visible range confirm the consistency of the similar $R_{\mathrm{f}}$ values of compounds separated. Although most of the selected species presented comparable chemical profiles, R. tetraphylla showed maximum similarity with $R$. serpentina.
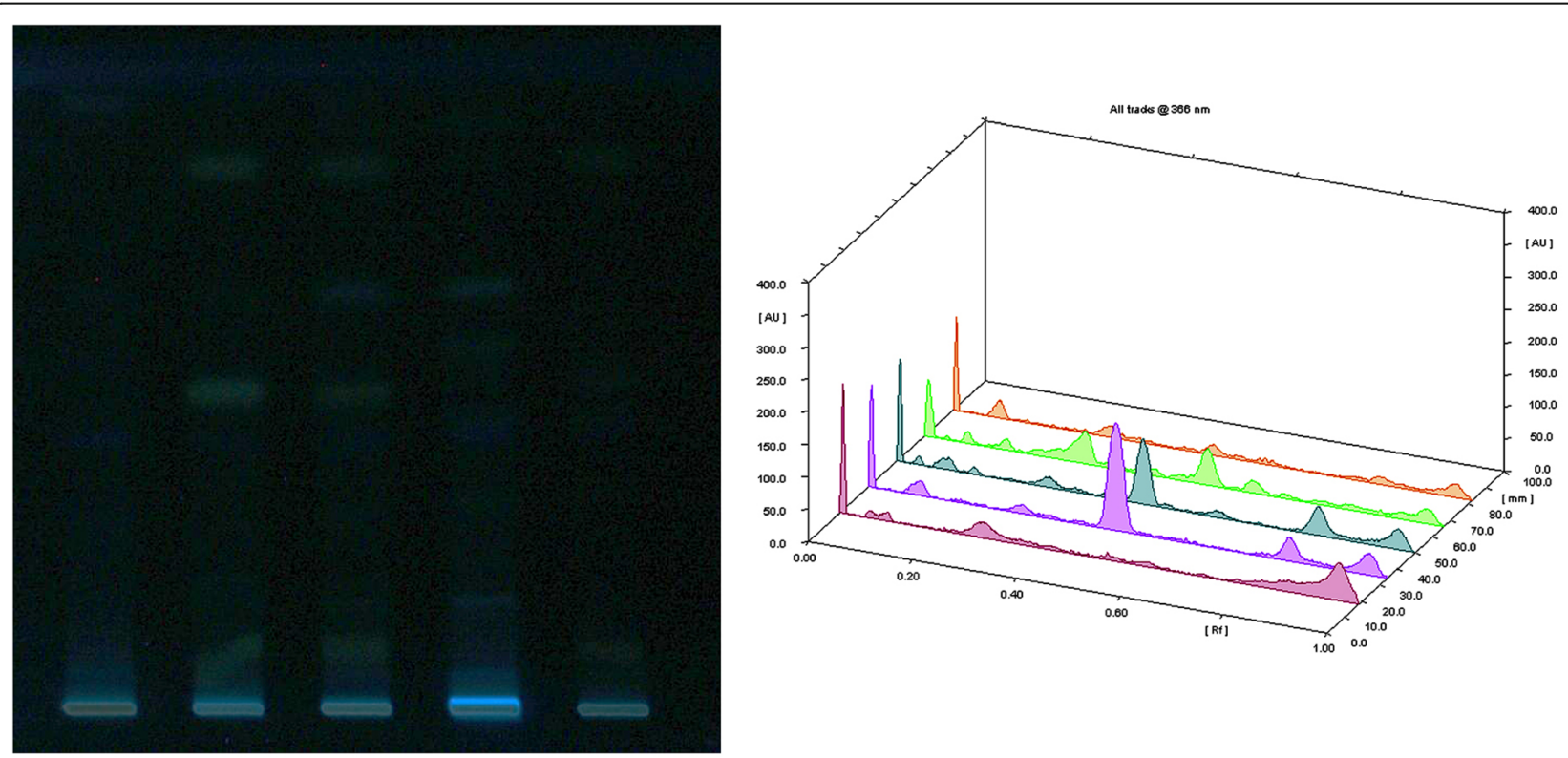

\section{RSR RHR RMR RTR RVR}

Fig. 3 HPTLC profile of aqueous extracts of various Rauvolfia species. RSR: $R$. serpentina root, RHR: $R$. hookeri root, RMR: $R$. micrantha root, RTR: $R$. tetraphylla root, RVR: $R$. verticillata root 


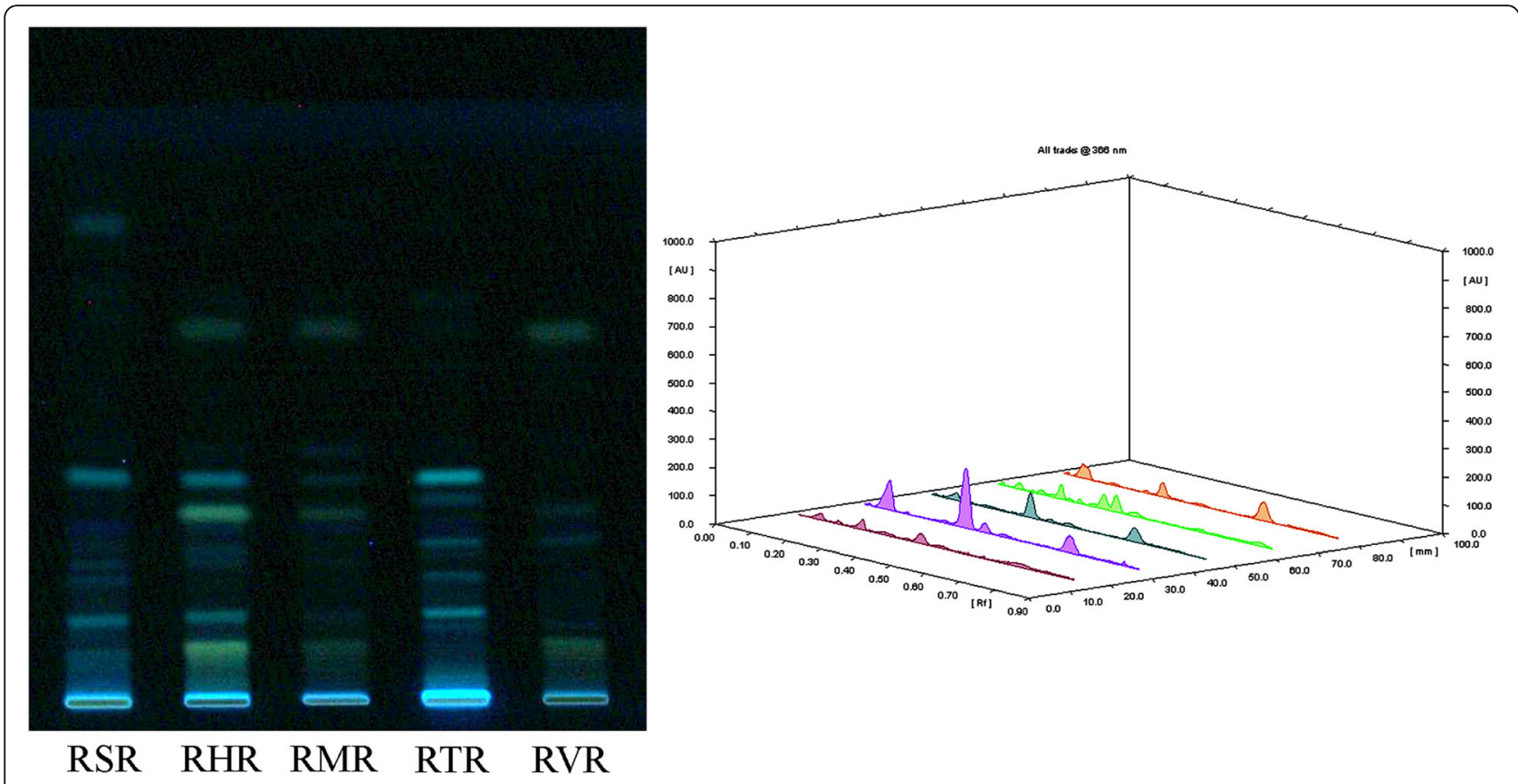

Fig. 4 HPTLC profile of hydro alcoholic extracts of various Rauvolfia species. RSR: R. serpentina root, RHR: R. hookeri root, RMR: R. micrantha root, RTR: R. tetraphylla root, RVR: $R$. verticillata root

Alkaloid fractions were screened separately by HPTLC with reserpine and ajmalicine as marker compounds. The chromatogram was documented and densitometry scanning was done at 254 and $366 \mathrm{~nm}$ (Fig. 5).

The evaluation of chromatographic profiles showed that most of the alkaloids are present in all the selected species. The species-specific indole alkaloids, reserpine, and ajmalicine are also detected in various species. Ajmalicine is present in all the species; however, the quantity of the same in $R$. tetraphylla is very less. Reserpine is found to be absent in $R$. verticillata.

The alkaloid fractions were subjected to LC/MS analysis for the detailed characterization. LC/MS analysis was done in ESI positive mode in order to obtain maximum ionization for alkaloids. Total ion chromatogram (TIC) obtained for MS analysis was extracted to base peak chromatogram (BPC) and integrated to record all the molecular ion peaks. The protonated molecular ions
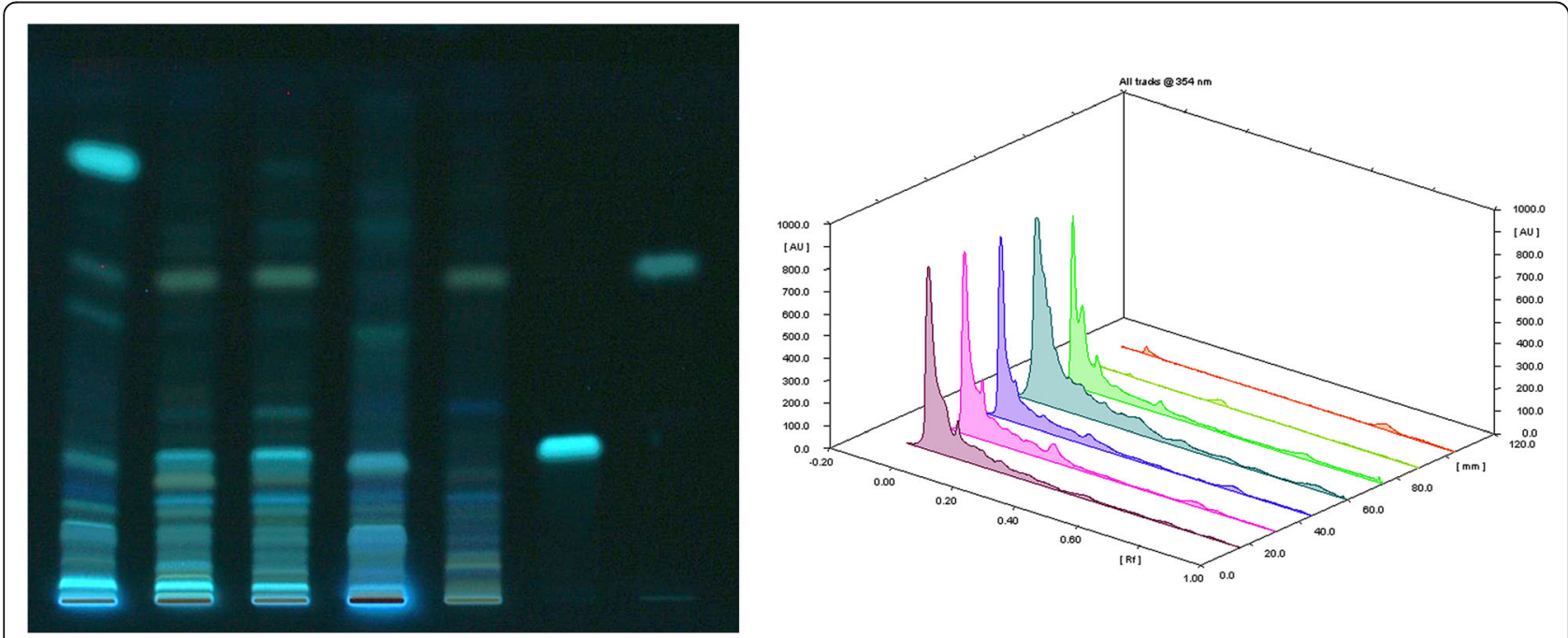

RSR RHR RMR RTR RVR R A

Fig. 5 HPTLC profiling of alkaloid fractions of selected Rauvolfia species with marker compounds. RSR: $R$. serpentina root, RHR: $R$. hookeri root, RMR: R. micrantha root, RTR: R. tetraphylla root, RVR: R. verticillata root, R: Reserpine, A: Ajmalicine 
with different $[\mathrm{M}+\mathrm{H}]$ values were evaluated and further characterization was carried out by MS/MS analysis. On MS/MS analysis, molecular ions were fragmented on collision induced dissociation (CID). It was noticed that most of the alkaloids were fragmented with a specific fragmentation pattern upon CID. The tentative structure was assigned based on MS/MS fragments obtained for each $[\mathrm{M}+\mathrm{H}]$ values (Table 5). The structure of alkaloids was identified by comparing the fragmentation pattern with that of previously reported ones [18, 19].

LC/MS analysis showed that most of the separated alkaloids are common for all the selected species. However, reserpine was not detected in $R$. verticillata. HPTL $\mathrm{C}$ and LC/MS analysis of alkaloid fractions confirmed that alkaloid profiles of most of the selected species are the same.

\subsection{Pharmacological evaluation}

\subsubsection{Anti-hypertensive activity}

Anti-hypertensive and analgesic activities of selected Rauvolfia species were studied in experimental animals. The anti-hypertensive activity of selected Rauvolfia species is presented in Table 6. A significant increase in both systolic and diastolic blood pressure was observed $(130 \pm 1.52 / 207 \pm 1)$ in DOCA-induced rats as compared to the normal group $(p<0.05)$. The standard drug enalapril reduced the diastolic and systolic pressure into $68 \pm 1$ and $126 \pm 1.52$ respectively. Root extract of $R$. serpentina administration attenuated the blood pressure induced by DOCA-salt significantly $(p<0.05)$. Root extract of $R$. tetraphylla significantly decreased both systolic and diastolic blood pressure $(92 \pm 1 / 121 \pm 1)$.

All the extracts showed reduction in systolic and diastolic pressure during the treatment. Root of $R$. serpentina, root extracts of $R$. hookeri, and $R$. tetraphylla reduced the diastolic pressure significantly which is comparable with that of standard drug.

\subsubsection{Analgesic activity}

Analgesic activity was screened by the formalin test and hot plate method. The treatment of mice with various extracts resulted in the inhibition of the formalininduced inflammatory pain. The result showed that the standard drug reduced the paw volume immediately within 10 min whereas $R$. tetraphylla and $R$. serpentina (GP IV and GP V) were able to reduce the paw volume within a period of $20 \mathrm{~min}$. This is followed by $R$. hookeri (GP III) and $R$. micrantha (GP VI). Paw reduction by $R$. verticillata (GP VII) is good when comparing to other drugs but it took $50 \mathrm{~min}$ and $60 \mathrm{~min}$ respectively to reduce the paw volume (Table 7). Root extract of $R$. tetraphylla significantly reduced the paw volume after $20 \mathrm{~min}$ which showed comparable analgesic activity with that of the genuine drug of Sarpagandha.

In hot plate method, rats treated with standard drug was able to tolerate the heat for a longer time. Almost similar result was obtained with $R$. micrantha (GP VI) followed by $R$. serpentina (GP V). All these groups work well at $60 \mathrm{~min}$ of treatment. Rauvolfia hookeri and $R$. tetraphylla showed better results respectively at $90 \mathrm{~min}$ (Table 8).

\section{Discussion}

In Ayurveda, the concept of substitution had explained when there is unavailability of any particular drug. The substitutes are of great economic importance in the herbal drug industry. The systematic identification and evaluation of substitutes for rare and endangered drugs by phytochemical and pharmacological studies is an important research area to ensure the quality of herbal products in the market.

In this study, detailed scientific investigations were carried out to find out a scientifically validated substitute for an important Ayurvedic drug which has been listed as endangered. The concept of substitution is usually

Table 5 LC/MS-MS analysis of alkaloid fractions of various Rauvolfia species

\begin{tabular}{|c|c|c|c|c|c|}
\hline Sl. no. & Compound & Molecular formula & $\mathrm{m} / \mathrm{z}[\mathrm{M}+\mathrm{H}]$ & MS/MS & Present in \\
\hline 1 & Reserpine & $\mathrm{C}_{33} \mathrm{H}_{40} \mathrm{~N}_{2} \mathrm{O}_{9}$ & 609.2913 & $577.23,436.16,174.20$ & RSR, RHR, RMR, RTR \\
\hline 2 & Yohimbinic acid & $\mathrm{C}_{20} \mathrm{H}_{24} \mathrm{~N}_{2} \mathrm{O}_{3}$ & 341.1849 & $323.17,192.10,144.07$ & RSR, RHR, RMR, RTR, RVR \\
\hline 3 & Reserpic acid methyl ester & $\mathrm{C}_{23} \mathrm{H}_{30} \mathrm{~N}_{2} \mathrm{O}_{5}$ & 415.2049 & $397.17,383.15,367.15$ & RSR, RHR, RMR, RTR, RVR \\
\hline 4 & $\begin{array}{l}\text { Methyl-14-hydroxy } 19 \text { methyl } 16,17 \\
\text { dihydro } 18 \text { oxayohimbin-16 carboxylate }\end{array}$ & $\mathrm{C}_{21} \mathrm{H}_{24} \mathrm{~N}_{2} \mathrm{O}_{4}$ & 369.1802 & $351.16,158.06,144.08$ & RSR, RHR, RMR, RTR, RVR \\
\hline 5 & Reserpic acid & $\mathrm{C}_{22} \mathrm{H}_{28} \mathrm{~N}_{2} \mathrm{O}_{5}$ & 401.2022 & $327.20,240.12,221.07,199.08,174.09$ & RSR, RHR, RMR, RTR, RVR \\
\hline 6 & Ajmalicine & $\mathrm{C}_{21} \mathrm{H}_{24} \mathrm{~N}_{2} \mathrm{O}_{3}$ & 353.1832 & $335.17,222.12,144.08,158.09$ & RSR, RHR, RMR, RTR, RVR \\
\hline 7 & Seredine & $\mathrm{C}_{23} \mathrm{H}_{30} \mathrm{~N}_{2} \mathrm{O}_{5}$ & 415.0201 & $383.18,224.13,173.08$ & RSR, RHR, RMR, RTR, RVR \\
\hline 8 & 18-hydroxy yohimbine & $\mathrm{C}_{21} \mathrm{H}_{26} \mathrm{~N}_{2} \mathrm{O}_{4}$ & 371.1952 & $339.17,240.12,144.08$ & RSR, RHR, RMR, RTR, RVR \\
\hline 9 & Yohimbine & $\mathrm{C}_{21} \mathrm{H}_{26} \mathrm{~N}_{2} \mathrm{O}_{3}$ & 355.2005 & $323.16,337.19,158.08,144.08$ & RSR, RHR, RMR, RTR, RVR \\
\hline 10 & Rescidine & $\mathrm{C}_{34} \mathrm{H}_{40} \mathrm{~N}_{2} \mathrm{O}_{9}$ & 621.0249 & $460.2,383.4,174.0$ & RSR, RHR, RMR, RTR, RVR \\
\hline 11 & Deserpidine & $\mathrm{C}_{32} \mathrm{H}_{238} \mathrm{~N}_{2} \mathrm{O} 8$ & 579.1808 & $367.2,448.1,195.4$ & RSR, RHR, RMR, RTR, RVR \\
\hline
\end{tabular}


Table 6 Anti-hypertensive activity of various Rauvolfia species

\begin{tabular}{|c|c|c|c|c|c|c|}
\hline \multirow[t]{2}{*}{ Groups } & \multicolumn{2}{|c|}{ Before induced with DOCA salt } & \multicolumn{2}{|c|}{ After induced with DOCA salt } & \multicolumn{2}{|c|}{ After treatment with plant extract } \\
\hline & Diastolic & Systolic & Diastolic & Systolic & Diastolic & Systolic \\
\hline Group I & $57 \pm 1$ & $110 \pm 1$ & $62 \pm 1$ & $114 \pm 1$ & $65 \pm 1$ & $110 \pm 1$ \\
\hline Group II & $61 \pm 2^{\#}$ & $112 \pm 1^{\#}$ & $113 \pm 1.52^{\#}$ & $177 \pm 1^{\#}$ & $130 \pm 1.52^{\#}$ & $207 \pm 1^{\#}$ \\
\hline Group III (enalapril) & $70 \pm 1$ & $117 \pm 1$ & $106 \pm 1$ & $167 \pm 1$ & $68 \pm 1^{*}$ & $126 \pm 1.52^{*}$ \\
\hline Group IV (RSR) & $63 \pm 0.7$ & $123 \pm 0.3$ & $93 \pm 0.7^{*}$ & $163 \pm 0.3^{*}$ & $81 \pm 0.4^{*}$ & $157 \pm 0.9$ \\
\hline Group V (RHR) & $67 \pm 1$ & $112 \pm 2$ & $101 \pm 1$ & $151 \pm 2$ & $78 \pm 1$ & $107 \pm 1$ \\
\hline Group VI (RMR) & $59 \pm 2$ & $113 \pm 0.7$ & $102 \pm 0.2$ & $173 \pm 0.7$ & $97 \pm 0.3$ & $151 \pm 0.23$ \\
\hline Group VII (RTR) & $66 \pm 1$ & $115 \pm 1.5$ & $103 \pm 1^{*}$ & $161 \pm 1.5^{*}$ & $92 \pm 1^{*}$ & $121 \pm 1^{*}$ \\
\hline Group VIII (RVR) & $65 \pm 1$ & $110 \pm 1$ & $97 \pm 1$ & $160 \pm 1$ & $89 \pm 0.3^{*}$ & $112 \pm 0.43^{*}$ \\
\hline
\end{tabular}

Values are mean $\pm S D, n=6$

$\# p<0.05$ when compared to GPI normal

${ }^{*} p<0.05$ when compared to GP-Il control by ANOVA followed by Dunnett's post-test

favored when the genuine drugs are not available or available in inadequate quantity. Rauvolfia serpentina was assessed as a critically endangered species in 2001. Encouraging herbal industries contingent on this species to support the development of sustainable utilization is an urgent need in the present scenario. Identification of a scientifically validated substitute for this species may help the industry to ensure the therapeutic efficacy and quality of the finished products. No such studies are reported in this species. A few reports are available regarding the chemical comparison of the selected species [20].

Comparative chemical profiling of different Rauvolfia species using tandem mass spectroscopic analysis has been reported earlier [18] and identification of alkaloids using mass spectroscopic characterization is in agreement with the present study. No comparative pharmacological studies have been reported in these species.
HPTLC and LC/MS analysis showed that allied species are rich in indole alkaloids and most of these alkaloids are found to be common for all the species. The same is in agreement with previous reports [20, 21]. Tandem mass spectroscopic analysis led to the identification of several alkaloids present in the selected species. The result showed that the root of $R$. tetraphylla is more similar in their chemical pattern with that of $R$. serpentina. Most of the active constituents including indole alkaloids such as reserpine, ajmalicine, yohimbine, and reserpic acid are also found in $R$. tetraphylla. Rauvolfia verticillata showed perceptible difference due to the absence of active compound reserpine.

Pharmacological evaluation such as anti-hypertensive activity and analgesic activity also supported the results of phytochemical analysis. Hypertension is a multifaceted disease that is involved in around $40 \%$ of cardiovascular mortalities and is the result of both genetic and

Table $\mathbf{7}$ analgesic activity of various Rauvolfia species by formalin test

\begin{tabular}{|c|c|c|c|c|c|c|c|c|c|c|c|c|}
\hline & \multicolumn{6}{|c|}{ Before treatment } & \multicolumn{6}{|c|}{ After treatment } \\
\hline & $10 \mathrm{~min}$ & $20 \min$ & $30 \mathrm{~min}$ & $40 \mathrm{~min}$ & $50 \mathrm{~min}$ & $60 \mathrm{~min}$ & $10 \mathrm{~min}$ & $20 \mathrm{~min}$ & $30 \mathrm{~min}$ & $40 \mathrm{~min}$ & $50 \mathrm{~min}$ & $60 \mathrm{~min}$ \\
\hline $\begin{array}{l}\mathrm{GPI} \\
\text { (control) }\end{array}$ & $15.0 \pm 1.4$ & $12.1 \pm 1.7$ & $5.8 \pm 1.1$ & $14.1 \pm 1.7$ & $12.0 \pm 1.7$ & $19.3 \pm 2.5^{\#}$ & $10.3 \pm 2.7$ & $3.1 \pm 1.9$ & $5.5 \pm 1.8$ & $2.5 \pm 1.6$ & $5.6 \pm 1.7$ & $10.6 \pm 3.7$ \\
\hline $\begin{array}{l}\text { GP \| } \\
\text { (Standard) }\end{array}$ & $1.5 \pm 0.5$ & $2.5 \pm 1.5$ & $2.6 \pm 1.5$ & $2.3 \pm 0.8$ & $2.0 \pm 1.2$ & $3.1 \pm 1.7$ & $1.3 \pm 1.2$ & $3.3 \pm 1.2$ & $3.0 \pm 1.4$ & $2.1 \pm 1.1^{*}$ & $2.6 \pm 1.7^{*}$ & $2.1 \pm 1.4^{*}$ \\
\hline $\begin{array}{l}\text { GP III } \\
\text { (RHR) }\end{array}$ & $10.6 \pm 1.7$ & $15.6 \pm 3.0$ & $13.1 \pm 3.1$ & $15.1 \pm 3.4$ & $10.6 \pm 1.7$ & $11.0 \pm 2.3$ & $14.0 \pm 2.2$ & $5.3 \pm 2.1$ & $4.8 \pm 2.0$ & $16.3 \pm 3.6$ & $12.0 \pm 2.6$ & $3.1 \pm 1.1^{*}$ \\
\hline $\begin{array}{l}\text { GP IV } \\
\text { (RTR) }\end{array}$ & $12.6 \pm 1.7$ & $16.6 \pm 4.0$ & $11.3 \pm 2.0$ & $10.6 \pm 2.1$ & $11.5 \pm 1.2$ & $18.6 \pm 1.8$ & $12.3 \pm 1.7$ & $1.8 \pm 1.1^{*}$ & $8.1 \pm 2.7$ & $10.5 \pm 2.8$ & $8.8 \pm 2.4$ & $3.5 \pm 1.0^{*}$ \\
\hline $\begin{array}{l}\text { GP V } \\
\text { (RSR) }\end{array}$ & $14.5 \pm 3.0$ & $14.8 \pm 1.9$ & $9.6 \pm 1.6$ & $10.8 \pm 1.6$ & $16.1 \pm 4.0$ & $10.0 \pm 2.2$ & $8.0 \pm 2.0$ & $6.0 \pm 1.2$ & $8.1 \pm 1.1$ & $6.1 \pm 2.4^{*}$ & $12.0 \pm 1.7$ & $8.8 \pm 1.8$ \\
\hline $\begin{array}{l}\mathrm{GP} \mathrm{Vl} \\
\text { (RMR) }\end{array}$ & $12.5 \pm 1.8$ & $13.3 \pm 2.4$ & $7.6 \pm 1.6$ & $7.6 \pm 2.2$ & $7.8 \pm 0.7$ & $7.5 \pm 1.8$ & $8.3 \pm 1.2$ & $5.8 \pm 2.1$ & $3.0 \pm 1.7^{*}$ & $1.6 \pm 1.0^{*}$ & $1.8 \pm 1.1^{*}$ & $1.8 \pm 0.7^{*}$ \\
\hline $\begin{array}{l}\text { GPVII } \\
\text { (RVR) }\end{array}$ & $7.5 \pm 1.5$ & $7.1 \pm 1.4$ & $8.1 \pm 2.4$ & $6.5 \pm 1.5$ & $7.5 \pm 1.0$ & $5.3 \pm 1.5$ & $2.5 \pm 1.8$ & $2.8 \pm 0.7^{*}$ & $2.1 \pm 0.7^{*}$ & $2.1 \pm 1.7^{*}$ & $1.3 \pm 0.8^{*}$ & $1.1 \pm 1.1^{*}$ \\
\hline
\end{tabular}

Values are mean $\pm \mathrm{SD}, n=6$

$\# p<0.05$ when compared to GPI normal

${ }^{*} p<0.05$ when compared to GP-II control by ANOVA followed by Dunnett's post-test 
Table 8 Analgesic activity of various Rauvolfia species by hot plate method

\begin{tabular}{lllll}
\hline & \multicolumn{4}{l}{ Reaction time in seconds at time (min) } \\
\cline { 2 - 5 } & 0 min & $60 \mathrm{~min}$ & $90 \mathrm{~min}$ & $120 \mathrm{~min}$ \\
\hline GP I (control) & $1.17 \pm 0.05$ & $1.22 \pm 0.12^{\#}$ & $1.28 \pm 0.16^{\#}$ & $1.38 \pm 0.19^{\#}$ \\
GP II (standard) & $1.46 \pm 0.09$ & $7.18 \pm 0.31$ & $6.62 \pm 0.35$ & $6.57 \pm 0.62$ \\
GP III (RHR) & $1.20 \pm 0.07$ & $5.61 \pm 0.36$ & $5.77 \pm 0.34$ & $5.38 \pm 0.30$ \\
GP IV (RTR) & $1.25 \pm 0.08$ & $5.38 \pm 0.50$ & $5.56 \pm 0.42$ & $5.35 \pm 0.29$ \\
GP V (RSR) & $1.29 \pm 0.08$ & $4.78 \pm 0.32$ & $4.88 \pm 0.53^{*}$ & $4.64 \pm 0.42^{*}$ \\
GP VI (RMR) & $1.30 \pm 0.06$ & $6.91 \pm 0.32$ & $6.88 \pm 0.30$ & $6.70 \pm 0.34$ \\
GPVII (RVR) & $1.45 \pm 0.08$ & $6.33 \pm 0.33$ & $6.28 \pm 0.32$ & $5.99 \pm 0.40^{*}$
\end{tabular}

Values are mean $\pm S D, n=6$

$\# p<0.05$ when compared to GPI normal

${ }^{*} p<0.05$ when compared to GP-Il control by ANOVA followed by

Dunnett's post-test

environmental factors [22]. In Ayurveda, Sarpagandha has been used for the treatment of high blood pressure for centuries. In the present study, anti-hypertensive activity of allied spices of $R$. serpentina was evaluated to identify a validated substitute for the same. Among the tested species, $R$. tetraphylla showed significant antihypertensive activity comparing to the genuine source of Sarpagandha and standard drug.

Inflammation and pain are common nonspecific manifestations of many diseases. In traditional medicines, several medicinal plants have been used to treat pain and inflammation [23]. Hot plate and formalin test are considered to be a reliable animal model for the evaluation of analgesic activity. The selected species were screened for their analgesic activity, and the result showed that most of the species having significant analgesic activity. Rauvolfia tetraphylla showed good analgesic activity when compared to $R$. serpentina. Analgesic activity also supported the possibility of using $R$. tetraphylla as substitute for the root of $R$. serpentina.

\section{Conclusion}

The study demonstrated that the genuine source drug of Sarpagandha is chemically and biologically similar with its allied species Rauvolfia tetraphylla. The active chemical components, specifically, indole alkaloids, are found to be common for both of these species. Pharmacological evaluations such as anti-hypertensive activity and analgesic activity also supported the phytochemical studies. In conclusion, these studies collectively recommend the possibility of using Rauvolfia tetraphylla as a scientifically validated substitute for Sarpagandha.

\section{Abbreviations}

BCG: Bromocresol green; DOCA: Deoxycorticosterone acetate; HPTLC: Highperformance thin-layer chromatography; LC-MS/MS: Liquid chromatographymass spectroscopy

\section{Acknowledgements}

The authors are thankful to Dr. Devaki K, Professor and Head, Department of Biochemistry, Karpagam University, Coimbatore, Tamil Nadu, India, for the support in pharmacological study. The financial assistance from the National Medicinal Plants Board, Ministry of AYUSH, Government of India (Project \# R\&D/KE-01/2015-16) is greatly acknowledged.

\section{Authors' contributions}

SCT: Designed the study carried out LC/MS analysis, pharmacological evaluation and drafted the manuscript. JCK: Carried out the phytochemical analysis. JKU: Participated in the phytochemical analysis. PKM: Collected the plant materials. IB: Participated in study designing and edited the manuscript. All authors have read and approved the manuscript.

\section{Funding}

The entire study was financially supported by the National Medicinal Plants Board, Ministry of AYUSH, Government of India (Project \# R\&D/KE-01/2015-

16) under the central sector R\&D program.

\section{Availability of data and materials}

The datasets used and/or analyzed during the current study are available from the corresponding author on reasonable request.

\section{Ethics approval and consent to participate}

The experimental procedures relating to the animals were authorized by the Committee for the Purpose of Control and Supervision of Experiments on Animals (CPCSEA) (Approval No: KAHE/IAEC/2018/21-04/002).

\section{Consent for publication}

Not applicable

\section{Competing interests}

The authors declare that they have no competing interests.

Received: 3 January 2020 Accepted: 28 July 2020

Published online: 13 October 2020

\section{References}

1. Bindu S, Rameshkumar KB, Kumar B, Singh A, Anilkumar C (2014) Distributionof reserpine in Rauvolfia species from India - HPTLC and LC-MS studies. Ind. Crops Prod 62:430-436

2. Nair VD, Panneerselvam R, Gopi R (2012) Studies on methanolic extract of Rauvolfia species from Southern Western Ghats of India - in vitro antioxidant properties, characterisation of nutrients and phytochemicals. Ind Crop Prod 39:17-25

3. Khare CP (2007) Indian medicinal plants, an illustrated dictionary, 2nd Edition, 539.

4. Pandeya DK, Dey RA (2016). A validated and densitometric HPTLC method for the simultaneous quantification of reserpine and ajmalicine in Rauvolfia serpentina and Rauvolfia tetraphylla. Revista Brasileira de Farmacognosia https://doi.org/10.1016/j.bjp.2016.04.002

5. Nishteswar K (2014) Depleting medicinal plant resources: a threat for survival of Ayurveda. Ayu 35(4):349-350

6. Prasad R, Patnaik S (1998). Conservation assessment and management planning. Proceeding of the Conservation Assessment and Management Planning (CAMP) workshop for non timber forest products in Madhya Pradesh, Indian Institute of Forest Management, Bhopal (M.P), 1-99.

7. Ram Manohar P (2012) Sustainable harvesting of medicinal plants: some thoughts in search for solutions. Anc Sci Life 32(1):1-2

8. Shamsa F, Monsef H, Ghamooshi R, Verdian-rizi M (2008) Spectrophotometric determination of total alkaloids in some Iranian medicinal plants. Thai J Pharm Sci 32:17-20

9. Singleton VL, Rossi JA (1965) Colorimetry of total phenolics with phosphomolybdic phosphotungstic acid reagents. Am J Enol Vitic 16:144-158

10. Sulaiman CT, Thushar KV, George S, Balachandran I (2014) Phenolic characterisation of selected Salacia species using LC-ESI-MS/MS analysis. Natural Product Research: Formerly Natural Product Letters 28(13):10211024 
11. Zhishen J, Mengcheng T, Jianming W (1999) The determination of flavonoid contents in mulberry and their scavenging effects on. Superoxide radicals Food chemistry 64:555-559

12. Balaraman R, Dangwal S, Mohan M (2006) Antihypertensive effect of Trigonella foenumgreacum seeds in experimentally induced hypertension in rats. Pharm Biol 44(8):568-575

13. Khanavi M, Delnavazi M, Nikoui V, Ostadhadi S, Bakhtiarian A (2012) Evaluation of analgesic effects of hydroalcoholic extract of Marrubium parviflorum by formalin test in mice. Asian J Plant Sci 11(2):96-99

14. Lobay D (2015) Rauwolfia in the treatment of hypertension. Integr Med (Encinitas) 14(3):40-46

15. Pundarikakshudu K, Bhatt CJ, Patel AK (2005) Spectrophotometric estimation of total alkaloids from Rauvolfia root powder and formulation. Indian J Pharm Sci 67(5):614-617

16. Cheung LM, Peter CK, Vincent EC (2003) Antioxidant activity and total phenolics of edible mushroom extracts. Food Chem 81 (2):249-255

17. Alali FQ, Tawaha K, El-Elimat T, Syouf M, El-Fayad M, Abulaila K, Nielsen SJ, Wheaton WD, Falkinham JO, Oberlies NH (2007) Antioxidant activity and total phenolic content of aqueous and methanolic extracts of Jordanian plants: an ICBG project Nat. Prod Res 21:1121-1131

18. Kumar S, Singh A, Bajpai V, Srivastava M, Singh BP, Kumar B (2016) Structural characterization of monoterpene indole alkaloids in ethanolic extracts of Rauwolfia species by liquid chromatography with quadrupole time-of-flight mass spectrometry. Journal of Pharmaceutical Analysis 6:363-373

19. Sun M, Liun J, Lin C, Miao L, Lin L (2014) Alkaloid profiling of the traditional Chinese medicine Rhizomacorydalis using high performance liquid chromatography-tandem quadrupole time-of-flight mass spectrometry. Acta PharmaceuticaSinica B 4(3):208-216

20. Kumar S, Singh A, Bajpai V, Kumar B (2016) Identification, characterization and distribution of monoterpene indole alkaloids in Rauwolfia species by Orbitrap Velos Pro mass spectrometer. J Pharm Biomed Anal 118:183-194

21. Kumara P M, Shaanker R U, Pradeep T (2018). UPLC and ESI-MS Analysis of Metabolites of Rauvolfia Tetraphylla L. And Their Spatial Localization Using Desorption Electrospray Ionization (DESI) Mass Spectrometric Imaging. Phytochemistry. https://doi.org/10.1016/.jphytochem.2018.11.009.

22. Basting T, Lazartigues E (2017) DOCA-Salt Hypertension: An Update. Curr Hypertens Rep 19(4):32.

23. Malairajan P, Gopalakrishnan G, Narasimhan S, Jessi Kala Veni K (2006) Analgesic activity of some Indian medicinal plants. J Ethnopharmacol 106: 425-428.

\section{Publisher's Note}

Springer Nature remains neutral with regard to jurisdictional claims in published maps and institutional affiliations.

\section{Submit your manuscript to a SpringerOpen ${ }^{\circ}$ journal and benefit from:}

- Convenient online submission

- Rigorous peer review

- Open access: articles freely available online

- High visibility within the field

- Retaining the copyright to your article

Submit your next manuscript at $\boldsymbol{\nabla}$ springeropen.com 